\title{
GIS AND REMOTE SENSING: A REVIEW OF APPLICATIONS TO THE STUDY OF THE COVID-19 PANDEMIC
}

\author{
Quoc-lap Kieu', Tien-thanh Nguyen ${ }^{2 *}$, Anh-huy Hoang ${ }^{3}$ \\ 'Faculty of Natural Resources and Environment, Thainguyen University of Sciences, Tan Thinh Ward, Thainguyen, \\ 250000, Vietnam \\ ${ }^{2}$ Faculty of Surveying, Mapping and Geographic Information, Hanoi University of Natural Resources and \\ Environment, No. 41A, Phu Dien Road, North-Tu Liem District, Hanoi,100000, Vietnam \\ ${ }^{3}$ Faculty of Environment, Hanoi University of Natural Resources and Environment, No. 41A, Phu Dien Road, North-Tu \\ Liem District, Hanoi, 100000, Vietnam \\ *Corresponding author: tdgis_ntthanh@163.com; ntthanh@hunre.edu.vn \\ Received: May 16 $6^{\text {th }}, 2021$ / Accepted: November 9 $9^{\text {th }}, 2021$ / Published: December $31^{\text {st }}, 2021$ \\ https://doi.org/10.24057/2071-9388-2021-054
}

\begin{abstract}
The spread of the 2019 novel coronavirus disease (COVID-19) has engulfed the world with a rapid, unexpected, and far-reaching global crisis. In the study of COVID-19, Geographic Information Systems (GIS) and Remote Sensing (RS) have played an important role in many aspects, especially in the fight against COVID-19. This review summarises 102 scientific papers on applications of GIS and RS on studies of the COVID-19 pandemic. In this study, two themes of GIS and RS-related applications are grouped into the six categories of studies of the COVID-19 including spatio-temporal changes, WebGISbased mapping, the correlation between the COVID-19 and natural, socio-economic factors, and the environmental impacts. The findings of this study provide insight into how to apply new techniques (GIS and RS) to better understand, better manage the evolution of the COVID-19 pandemic and effectively assess its impacts.
\end{abstract}

KEYWORDS: GIS; remote sensing; applications; COVID-19; viral infection; impacts; environment

CITATION: Quoc-lap Kieu, Tien-thanh Nguyen, Anh-huy Hoang (2021). Gis And Remote Sensing: A Review Of Applications To The Study Of The Covid-19 Pandemic. Geography, Environment, Sustainability, Vol.14, No 4, p. 117-124

https://doi.org/10.24057/2071-9388-2021-054

ACKNOWLEDGEMENTS: We wish to thank the editors and anonymous reviewers for their valuable and constructive comments and suggestions on this paper that have helped us to greatly improve the quality of the paper.

Conflict of interests: The authors reported no potential conflict of interest.

\section{INTRODUCTION}

The COVID-19 pandemic has been a global health concern due to the rapid spread of the disease (WHO 2020) since a deadly new coronavirus strain, the SARSCoV-2 virus was initially discovered in Wuhan city, PR China. The COVID-19 pandemic has been described as a social, human, and economic crisis (United Nations 2020). Globally, as of October 22, 2021, there were more than 242.3 million confirmed cases of the COVID-19, including more than 4.9 million deaths reported to $\mathrm{WHO}$ (WHO 2021). Geography is considered a key part of fighting the COVID-19 Coronavirus outbreak (Shepherd 2020). Later, Rose-Redwood et al. (2020) highlight that the COVID-19 pandemic is thoroughly spatial in nature. It is, therefore, the assessment of the scale of the COVID-19 pandemic from a geographical perspective that can offer a better understanding of the spatial distribution, better manage the COVID-19 infection, and effectively study its impacts. A Geographic Information System (GIS) is an essential tool to examine the spatial distribution of spatial objects. Many COVID-19-related data such as the locations of (visited) COVID-19 cases can be considered a type of spatial object which has a spatial dimension and can be mapped by a GIS. When assessing potential geographical accessibility for health utilization studies, Graves (2012) showed the importance of GIS in analyzing epidemiological data, revealing trends and interrelationships that would be difficult to discover in tabular format and the visualization of problems in relation to existing health and social services and the natural environment and so more effectively target resources. Later, the use of GIS in geospatial health has been also firmly established as a useful tool for collating, exploring, visualizing, and analyzing health data in a graphic manner (Cicalò and Valentino 2019). Along with GIS, remote sensing allows acquiring information about the Earth's surface without actually being in contact with it. The applications of remote sensing data to studies of human health, especially in infectious disease research have been reviewed by Viana et al. (2017). It is, therefore, GIS and remote sensing data are fundamental to keep infectious diseases and their geographical distribution under control (Cicalò and Valentino 2019). In this study, to understand the spatial patterns, effects, and consequences of COVID-19 in the context of geography, this study aims to review the applications of GIS and remote sensing in the study of the COVID-19 pandemic. In this study, we first review the applications of GIS to detect the spatio-temporal changes, Web-GIS-based mapping of the COVID-19, and the identification of the correlation between the 
COVID-19 and natural, social-economical variables. It will then go on to discuss the applications of remote sensing techniques on the environmental impacts of the COVID. The environmental impacts of the COVID-9 will mainly focus on studies of its impacts on water and air quality.

\section{APPLICATIONS OF GIS IN THE STUDY OF THE COVID-19 PANDEMIC}

\section{Spatio-temporal changes}

GIS can help to study the COVID-19 epidemic spread at the country or state scale (Kodge 2021; Saeed et al. 2021), at the regional scale (Amdaoud et al. 2021; Onafeso et al. 2021), and at the global scale (Bisanzio et al. 2020; Gelfand et al. 2021; Meng 2021). When the SARS-CoV-2 virus was initially discovered at the end of 2019 in Wuhan city, Hubei province, central China, and quickly spread throughout China, application studies of GIS on the fight of the COVID-19 pandemic in China have been conducted by many authors. One of the most cited studies was carried out by Guan et al. (2020). With the help of GIS, Guan et al. (2020) extracted data regarding 1099 patients with laboratoryconfirmed Covid-19 from 552 hospitals in 30 provinces, autonomous regions, and municipalities in mainland China through January 29, 2020. Later, by analyzing the spatial distribution of COVID-19 cases in the early stages of the epidemic and determining their correlation with the population migration from Wuhan city and Hubei province using ArcGIS software and the Bayesian space-time model, Chen et al. (2020) concluded that the population that emigrated from Wuhan was the main infection source in other cities and provinces. This is of great importance for strictly implementing isolation or social distancing rules and early warning and prevention of future outbreaks. After COVID-19 rapidly spread across China and the rest of the world, many studies make use of GIS to detect the spatio-temporal changes in many countries, especially in the worst-affected countries such as the USA (Feng et al. 2020; Rui et al. 2021; Wang et al. 2021), Italy (Giuliani et al. 2020; Gross et al. 2020; He et al. 2020), England (Elson et al. 2021; Sartorius et al. 2021), South Korea (He et al. 2020; Kim and Castro 2020; Lee et al. 2020), Iran (He et al. 2020), Brazil (Castro et al. 2021), Russia (Kuznetsov et al. 2020a) and most recently in India (Bag et al. 2020; Bhunia et al. 2021).

When characterizing the dynamics and quantifying the trends of the COVID-19 epidemic in the United States using spatial and space-time scan statistics and the Joinpoint analysis, Wang et al. (2021) indicate that higher risks of clustering and incidence of COVID-19 were consistently observed in metropolitan versus rural counties, counties closest to core airports, the most populous counties, and counties with the highest proportion of racial/ethnic minorities. Feng et al. (2020) revealed that GIS can help to effectively characterize spatio-temporal transmission of COVID-19 and its mitigation strategies. Most recently, when analyzing the spread of COVID-19 in the USA, Rui et al. (2021) found that the spatio-temporal multivariate time-series model is especially suitable for envisioning the virus transmission tendency across a geographic area over time. Using an endemic-epidemic multivariate timeseries mixed-effects generalized linear model for areal disease counts, Giuliani et al. (2020) successfully modeled and predicted the spatio-temporal spread of COVID-19 in Italy. In the early stages of the COVID-19 pandemic between January and June 2020 in England, using spatial and spatio-temporal kernel estimates developed by Davies and Lawson (2019), Elson et al. (2021) discovered the spatio-temporal distribution of COVID-19 infection. In Brazil, Castro et al. (2021) successfully used daily data on reported cases and deaths to understand, measure, and compare the spatio-temporal pattern of the spread across municipalities. In South Korea, to understand the COVID-19 clustering across districts in South Korea and how the spatial pattern of COVID-19 changes, Kim and Castro (2020) successfully applied the global Moran's I statistic and the retrospective space-time scan statistic to analyze spatio-temporal clusters of COVID-19. Most recently, when identifying spatial patterns of COVID-19 disease clustering in India using another global spatial autocorrelation statistic, the Getis-Ord G* statistic, Bhunia et al. (2021) discovered that this statistic can help public health professionals to effectively identify risk areas for disease and take decisions in real-time to control this viral disease.

\section{WebGIS-based mapping}

When considering the usage of Web-based (or WebGIS-based) mapping during the COVID-19 pandemic, Mooney and Juhász (2020) concluded that Web-GIS maps have been widely used for delivering public information on this fast-moving, epidemiologically complex, and geographically unbounded process. Similar to those reported by Mooney and Juhász (2020), Franch-Pardo et al. (2020) also showed the importance of WebGISbased mapping in the dissemination and provision of (official) information on COVID-19, especially for the spatial representation of the pandemic and its evolution. When conducting a study on geographical tracking and mapping of coronavirus disease COVID-19/SARS-CoV-2 epidemic and associated events around the world, Boulos and Geraghty (2020) successfully employed different types of WebGIS-based mapping such as practical online/mobile GIS and mapping dashboards for tracking the 2019/2020 coronavirus epidemic. According to Franch-Pardo et al. (2020), the most international information compiled, the most widely referenced viewer, and the first to go online out is an interactive WebGIS-based dashboard to track COVID-19 in real-time developed by John Hopkins University (see Dong et al. (2020) for more detail). At the same time, Cicalò and Valentino (2019) successfully used the web-based for the study of epidemics and design of the web maps on COVID-19. Since then, more WebGISbased applications for mapping COVID-9 have been created for each country such as Russia (Kuznetsov et al. 2020a; Momynaliev et al. 2021), the USA (Cicalò and Valentino 2019; Gao et al. 2020), China (Xu et al. 2020), UK (Mooney and Juhász 2020), Israel (Rossman et al. 2020) and Italy (Mooney and Juhász 2020).

Typically, to obtain a real-time nationwide view of symptoms across the entire population in Israel, an online questionnaire was employed in a study by Rossman et al. (2020) to identify geographic clusters in which the virus is spreading. This study is potential for the detection of COVID-19 outbreaks. And recently, to help increase risk awareness of the public, support data-driven public health and governmental decision-making, and help enhance community responses to the COVID-19 pandemic, Gao et al. (2020) successfully used daily updated human mobility statistical patterns derived from large-scale anonymized and aggregated smartphone location big data at the countylevel in the United States to provide timely quantitative information on how people in different counties and states reacted to the social distancing guidelines.

In Russia, a number of authors have successfully applied WebGIS to mapping the COVID-19 epidemic. 
Kuznetsov et al. (2020b) focused on the investigation and design of the methodology and software prototype for GIS-based support of medical administration and planning on a city scale when accounting and controlling infectious diseases. Later, with the aim of evaluating the usefulness of Internet queries related to the smell to assess the effectiveness of anti-epidemic measures of preventing the spread of COVID-19 in some regions of Russia, Momynaliev et al. (2021) concluded that the rise in the sudden interest in smell among Internet users can be seen as a valuable minimally invasive indicator of the spread of the coronavirus in the population, as well as to assess the effectiveness of anti-epidemic measures against COVID-19. WebGIS for mapping the COVID-19 pandemic has been also proved effective by other scholars (Bachilo et al. 2020; Nekliudov et al. 2020).

\section{Identification of correlations between COVID-19 and natural, socio-economic factors}

To analyze the correlation between confirmed cases of COVID-19 and several geographic, meteorological, and socio-economic variables at the province level in Spain, Oto-Peralías (2020) points out that the arrival of the summer heat may play in limiting the spread of the virus. From a different angle, using GIS-based approaches such as spatial lag and spatial error models to investigate spatial dependence and multiscale geographically weighted regression models to locally examine spatial non-stationarity, Mollalo et al. (2020) point out the effects of significant explanatory variables (income inequality, median household income, the proportion of black females, and the proportion of nurse practitioners) on a relatively high spatial variability of COVID-19 incidence rates in the continental United States. Also in the United States, when investigating the correlation between the geographic spread of COVID-19 and the structure of social networks as measured by Facebook, Kuchler et al. (2020) concluded that a social connectivity index can help epidemiologists predict the spread of communicable diseases.

In the first COVID-19 wave, Russia has the thirdhighest number of confirmed cases after the United States and Brazil (Pramanik et al. 2020). Many contributions to apply GIS in the fight against the second COVID-19 wave have been made by scholars in Russia. Typically, using the Random Forest algorithm, Pramanik et al. (2020) successfully investigated the relationship between climatic factors (air temperature, relative humidity, wind speed, sunshine, diurnal temperature change, and temperature seasonality) and the rise of COVID-19 intensity. Later, when investigating the meteorological controls on the spread of SARS-CoV-2 in Russia using correlation analysis and factor analysis, Shankar et al. (2021) indicated that the increase of temperature increases the spreading and the decreased humidity with increase death rates. Spatial dynamics and diffusion factors across Russian regions were analyzed in a study by Zemtsov and Baburin (2020). In that study, Zemtsov and Baburin (2020) have revealed that the SARSCoV-2 has spread faster in regions where the population has a higher susceptibility to diseases.

When India experienced the third wave of COVID-19, much effort has been put into the identification of correlations between COVID-19 and natural, socioeconomic factors. Using GIS-based proximity analysis and census data of Jaipur city and socio-economic parameters (population, population density, percentage of main workers, and percentages of literates), Kanga et al. (2021) researched the risk of COVID-19 infection utilizing integrated hazard and vulnerability components associated with this pandemic for effective risk mitigation. Also in India, using a GIS-based geostatistical approach, risk analysis of COVID-19 infections in Kolkata Metropolitan city was carried out by Nath et al. (2021). With the help of GIS-based approaches in combination with related socio-economic variables, extensive studies on the risk assessment to COVID-19 infection have been conducted in many badly-affected countries by COVID-19 such as the United States (Ali et al. 2021b; DuClos et al. 2021), Italy (Tiboni et al. 2020), England (Sartorius et al. 2021), Brazil (Gomes et al. 2020; Martines et al. 2021), Peru (BadilloRivera et al. 2020), India (Kanga et al. 2021; Nath et al. 2021) and Bangladesh (Masrur et al. 2020; Rahman et al. 2021a).

\section{APPLICATIONS OF REMOTE SENSING IN THE STUDY OF THE COVID-19 PANDEMIC}

\section{Studies of impacts on water quality}

When the SARS-CoV-2 virus was initially identified in December 2019 in Wuhan city, China, and quickly spread throughout China Sivakumar (2021) point out that the spread of COVID-19 will increase the water demand and worsen the water quality, leading to additional challenges in water. It is, therefore, the impacts of the COVID-19 pandemic on water quality employing remote sensing techniques have been studied by many authors in China. One of the first studies on the impacts of the COVID-19 on water quality in China was carried out by Avtar et al. (2020) to quantitatively estimate the chlorophyll-a (Chl-a) concentrations in different lake bodies of Wuhan, China. In that study, Avtar et al. (2020) concluded that there was an elevated concentration of Chl-a during the COVID-19 lockdown. Also in Wuhan city, Sun et al. (2021) employed multi-sensor satellite images (Landsat-8/OLI, Sentinel-2/ $\mathrm{MSI}$, and $\mathrm{HY}-1 \mathrm{C} / \mathrm{CZI}$ ) to estimate the turbidity of lakes. It was found that the mean turbidity showed a $24.9 \%$ decline from 33.4 NTU to 25.1 NTU after the lockdown in Wuhan, which dropped $16.0 \%$ compared to that in the previous year (Sun et al. 2021). Later, when investigating the lockdown effects of the COVID-19 on total suspended solids (TSS) concentrations in the Lower Min River (China) during COVID-19 using different multi-temporal optical remotely sensed images acquired from November 2019 to April 2020 such as Landsat-5 Thematic Mapper (TM), Landsat-8 Operational Land Imager (OLI), and China's GaoFen-1 (GF-1) Wide Field of View (WFV) images, Xu et al. (2021) indicated that the lockdown measures have resulted in a 48\% fall in TSS concentrations in February 2020. Xu et al. (2021) also concluded that industrial production, social and economic activities, and river shipping appear to be the main factors contributing to the river's TSS decline in the lockdown period. These findings were consistent with those reported in a most recent study of Liu et al. (2022) that COVID-19 lockdown improved river water quality in China.

After the SARS-CoV-2 virus quickly spread across the globe, this problem has received much attention from several authors in the worst-affected countries such as India, Spain, and Italy. To understand the effects of COVID-19 lockdown, Wagh et al. (2021) assessed the indicative lake water quality for the Lake Hussain Sagar (India) using Landsat-8 sensor Operational Land Imager (OLI). This study results have shown that there were a reduction in Chlorophyll-a (Chl-a) and Colored Dissolved Organic Matter (CDOM) concentrations and a significant reduction in lake water pollution (Wagh et al. 2021). From 
the above discussion, it can be concluded that there has been an improvement in the water quality during the COVID-19 lockdown. These findings were consistent with those reported by many studies (Arif et al. 2020; Najah et al. 2021; Yunus et al. 2020). In this study, Adwibowo (2020) investigated the effects of social distancing on water quality in the Jakarta coast based on remote sensing data captured by Copernicus Sentinel-3B Ocean and Land Color Instrument in January and February of 2020, Adwibowo (2020) figured out that there were reductions of levels and areas of chlorophyll-a in the coast as a function of social distancing and activity restrictions. Weeks later, with the help of Sentinel-2A images and the ArcGIS software, Parra Boronat (2020) conducted a study on the effects of before (since February 3rd, 2020) and during (until June 22nd, 2020) the quarantine caused by COVID-19 on the Alboran Sea (Spain). The study results of Parra Boronat (2020) indicated that seawater quality has been improved after the quarantine caused by COVID-19. Later, to study the impacts of the 2020 COVID-19 lockdown and the 2019 extreme flood in the Venice lagoon (northeast Italy), Niroumand-Jadidi et al. (2020) employed Planet Scope imagery to retrieve water quality. The results of NiroumandJadidi et al. (2020) have shown that a remarkable reduction of the turbidity during the lockdown, due to the COVID-19 pandemic and capture the high values of total suspended matter (TSM) during the flood condition. Using Sentinel-2A, -2B, and optical satellite data, Tripathi et al. (2020) showed that the Ganga River's water quality has been improved during COVID-19 lockdowns in India (24th March to 18th May 2020) while comparing with the normal days.

\section{Studies of impacts on air quality}

In the early stages of the COVID-19 pandemic initially discovered in Wuhan city, PR China, nitrogen dioxide $\left(\mathrm{NO}_{2}\right)$ concentrations estimated from remotely sensed images had been proved to fall by as much as 30\% across China and by as much as $50 \%$ across areas of central Europe (NASA 2020). Later, one of the first studies on the impacts of the COVID pandemic on air quality was carried out by Talukdar et al. (2020). When modeling the global air quality conditions in the perspective of COVID-19 stimulated lockdown periods using MERRA-2and AIRS data, Talukdar et al. (2020) concluded that amid lockdown aerosol optical depth (AOD), sulfur dioxide $\left(\mathrm{SO}_{2}\right)$, ozone, carbon monoxide (CO), particulate matter $\left(\mathrm{PM}_{25}\right)$, and black carbon (BC) concentration level have been significantly reduced in fully lockdown countries. Later, studies on specific countries and regions through remotely sensed images were gradually reported. One of the Google Scholar rankings of most highly cited studies on spatio-temporal patterns of COVID-19 impact on human activities and environment in mainland China using nighttime light and air quality data was carried out by Liu et al. (2020). In that study, Liu et al. (2020) discovered a significant decreasing trend in the daily average Air Quality Index for mainland China from January to March 2020, with cleaner air in most provinces during February and March, compared to January 2020. With the help of satellite data, Zheng et al. (2020) estimated the decline and rebound in China's $\mathrm{CO}_{2}$ emissions during the COVID-19 pandemic. Similar to those reported in a study by Zheng et al. (2020), Chen et al. (2021) also revealed the driving force of China's $\mathrm{CO}_{2}$ emissions fell by more than 40\% compared with the same period in 2019 when the city was closed from the end of January to the beginning of 2020.
Using the ground-based remote sensing techniques, lonov et al. (2021) found that there was a decrease in $\mathrm{CO}_{2}$ emission obtained during the COVID-19 lockdown period in 2020 and the same period of 2019 in the city of St. Petersburg, Russia. Singh et al. (2020) explored the dynamics of different air pollutants and qualitatively highlight potential links with COVID-19 pressures during different phases of the pandemic in Russia using Sentinel-5P based datasets. It was found that regional concentrations of $\mathrm{NO}_{2}$ and $\mathrm{O}_{3}$ increased significantly, in some cases by more than $50 \%$ during the "lockdown" in Russia. Employing OMI and AIRS data to estimate the extent of the reduction of major pollutants such as carbon monoxide, nitrogen dioxide, and sulfur dioxide in the south-east Asian regions from January to April 2020, Metya et al. (2020) discovered air quality improved in India and China during the COVID-19 outbreak in which $\mathrm{NO}_{2}$ was reduced the most; $\mathrm{CO}$ to some extent and $\mathrm{SO}_{2}$ experienced a nominal reduction. Similar to those reported by Metya et al. (2020), there were also a decrease in $\mathrm{NO}_{2}$ in the Beijing-Tianjin-Hebei region and most of Northeast and Central China during COVID-19 (Nichol et al. 2020) and drastic reductions in $\mathrm{NO}_{2}$ (up to $-54.3 \%$ ) in the urban area during partial lockdown (Nakada and Urban 2020). Using low spatial resolution images, Das et al. (2020) have shown that most of the countries, for example, Italy, Spain, Germany, the UK, the USA, Russia, India, Mexico, China, Australia, Brazil show a decreasing trend of $\mathrm{NO}_{2}$ during COVID-19 lockdown in March 2020 when comparing with those obtained from the previous year. Most recently, when investigating the COVID-19 transmission change under different lockdown scenarios in Dhaka city, Bangladesh, study results of Rahman et al. (2021b) showed that overall, 26, 20.4, 17.5, 9.7, and 8.8\% declined in $\mathrm{PM}_{25}, \mathrm{NO}_{2}, \mathrm{SO}_{2}, \mathrm{O}_{3}$, and $\mathrm{CO}$ concentrations, respectively, in Dhaka City during the partial and full lockdown compared to the period before the lockdown. Late work using different types of remotely sensed images also confirmed the air quality improvement during the COVID-19 lockdown, quarantine, and social distancing, with studies from badly affected countries such as England (Wyche et al. 2021), Italy (Filippini et al. 2020; Sannino et al. 2020), Brazil (Brito et al. 2020), and most recently India (Naqvi et al. 2021; Sathe et al. 2021).

\section{Studies of other impacts on the environment}

Apart from the main impacts on water and air quality as reviewed above, using remotely sensed images, many studies have been conducted on the other environmental impacts of the COVID-19 pandemic such as urban heat islands (Ali et al. 2021a; Alqasemi et al. 2021; Teufel et al. 2021) and ecology (Firozjaei et al. 2021). In the study of urban heat islands, when conducting a study on the remote sensing-based assessment of changes in urban heat island effect associated with the lockdown implementations to retard the spread of the COVID-19 virus in Pakistan, Ali et al. (2021a) had come to a conclusion that restrictions on transportation in the cities resulted in an evident drop in the surface urban heat island effect, particularly in megacities. This finding is consistent with those recently reported in studies of Alqasemi et al. (2021) using the Level 2 Sentinel 5P data in the United Arab Emirates and of Teufel et al. (2021) using MODIS images in Montreal (Canada). Most recently, in the study of ecological status, the impact of the COVID-19 lockdowns on urban surface ecological status in Milan and Wuhan cities was assessed in the research of Firozjaei et al. (2021). It was found that, due to the COVID-19 lockdowns, built-up, bare 
soil, and green spaces for Milan and Wuhan dramatically decreased (Firozjaei et al. 2021). To investigate the effect of lockdown during COVID-19 on land surface temperature using the TIRS sensor data acquired during the COVID-19 lockdown and post-lockdown in Dehradun city, India, Maithani et al. (2020) discovered that there was an increase in a number of hot spots accompanied by a decrease in thermal comfort level post-lockdown. In Russia, one of the most affected country by COVID-19, when studying the reduction of surface radiative forcing observed from remote sensing data during global COVID-19 lockdown in April 2020, Mazhar et al. (2021) revealed that aerosol optical depth and $\mathrm{NO}_{2}$ shows a significant increase in some part of Russia. Also in Russia, when comparing environmental noise measurements in urban conditions before and during the COVID-19 period, Vasilyev (2021) indicated that transport noise level is reduced, but the industrial noise level is almost the same, especially in low-frequency range. These findings were also consistent with those reported in the worst-affected countries such as China (Fan et al. 2020; Filonchyk et al. 2020), the United States (Acharya et al. 2021; Wei et al. 2020), and European countries (Li et al. 2020).

\section{CONCLUSIONS}

This study is an addition to studies of the applications of GIS and remote sensing on the COVID-19 pandemic. Two themes of GIS and RS-related applications are grouped into six categories of the COVID-19-related studies including spatio-temporal changes, WebGIS-based mapping, the identification of the correlation between the COVID-19 pandemic and natural, socio-economical variables using GIS, and the use of remote sensing to assess the environmental impacts of the COVID-19. GIS methods play an important role in COVID-19 related-decision-making, more importantly, social mobilization and community responses. COVID-19 studies with remote sensing can be an effective tool in the assessment of the impacts of COVID-19. This study provides insight and a better understanding of the applications of GIS and RS on studies of the COVID-19 pandemic. It can be concluded from this review that both GIS and RS have played an important role in many aspects of COVID-19 studies, especially in the fight against COVID-19.

\section{AUTHOR CONTRIBUTIONS}

Quoc-lap Kieu conceived, designed, and prepared the research. Tien-thanh Nguyen carried out the formal analysis, wrote and edited the manuscript. Anh-huy Hoang supervised the research and provided conceptual advice. All authors discussed the results, implications and commented on the manuscript at all stages.

\section{REFERENCES}

Acharya P et al. (2021). Revisiting the levels of Aerosol Optical Depth in South-Southeast Asia, Europe and USA amid the COVID-19 pandemic using satellite observations Environmental research,193(110514).

Adwibowo A (2020). Does social distancing have an effect on water quality?: An evidence from Chlorophyll-a level in the water of populated Southeast Asian coasts.

Ali G, Abbas S, Qamer F.M, Wong M.S, Rasul G., Irteza S.M, Shahzad N. (2021a). Environmental impacts of shifts in energy, emissions, and urban heat island during the COVID-19 lockdown across Pakistan Journal of Cleaner Production, 291(125806).

Ali T., Mortula M., Sadiq R. (2021 b). GIS-based vulnerability analysis of the United States to COVID-19 occurrence Journal of Risk Research, 1-16.

Alqasemi A.S., Hereher M.E., Kaplan G., Al-Quraishi A.M.F., Saibi H. (2021). Impact of COVID-19 lockdown upon the air quality and surface urban heat island intensity over the United Arab Emirates Science of The Total Environment, 767(144330).

Amdaoud M., Arcuri G., Levratto N. (2021). Are regions equal in adversity? A spatial analysis of spread and dynamics of COVID-19 in Europe The European Journal of Health Economics, 1-14.

Arif M., Kumar R., Parveen S., Verma N. (2020). Reduction in water pollution in Yamuna river due to lockdown under COVID-19 pandemic ChemRxiv Preprint.

Avtar R., Kumar P., Supe H., Jie D., Sahu N., Mishra B.K., Yunus A.P. (2020). Did the COVID-19 lockdown-induced hydrological residence time intensify the primary productivity in lakes? Observational results based on satellite remote sensing Water, 12(2573).

Bachilo E., Barylnik J., Shuldyakov A., Efremov A., Novikov D. (2020). Mental health of medical workers during the COVID-19 pandemic in Russia: Results of a cross-sectional study medRxiv.

Badillo-Rivera E., Fow-Esteves A., Alata-López F., Virú-Vásquez P., Medina-Acuña M. (2020). Environmental and social analysis as risk factors for the spread of the novel coronavirus (SARS-CoV-2). using remote sensing, GIS and analytical hierarchy process (AHP): Case of Peru medRxiv.

Bag R., Ghosh M., Biswas B., Chatterjee M. (2020). Understanding the spatio-temporal pattern of COVID-19 outbreak in India using GIS and India's response in managing the pandemic Regional Science Policy \& Practice, 12, 1063-1103.

Bhunia G.S., Roy S, Shit PK (2021). Spatio-temporal analysis of COVID-19 in India-a geostatistical approach Spatial Information Research, $1-12$.

Bisanzio D., Kraemer M.U., Bogoch II, Brewer T., Brownstein J.S., Reithinger R. (2020). Use of Twitter social media activity as a proxy for human mobility to predict the spatiotemporal spread of COVID-19 at global scale Geospatial health 15.

Boulos M.N.K., Geraghty E.M. (2020). Geographical tracking and mapping of coronavirus disease COVID-19/severe acute respiratory syndrome coronavirus 2 (SARS-CoV-2) epidemic and associated events around the world: how 21st century GIS technologies are supporting the global fight against outbreaks and epidemics. BioMed Central.

Brito P.L., Kuffer M., Koeva M., Pedrassoli J.C., Wang J., Costa F., Freitas A.Dd. (2020). The Spatial Dimension of COVID-19: The Potential of Earth Observation Data in Support of Slum Communities with Evidence from Brazil ISPRS International Journal of Geo-Information, 9(557).

Castro M.C. et al. (2021). Spatiotemporal pattern of COVID-19 spread in Brazil Science.

Chen J., Gao M., Huang S., Hou W. (2021). Application of remote sensing satellite data for carbon emissions reduction Journal of Chinese Economic and Business Studies, 1-9.

Chen Z-L et al. (2020). Distribution of the COVID-19 epidemic and correlation with population emigration from Wuhan, China Chinese medical journal.

Cicalò E., Valentino M. (2019). Mapping and visualisation on of health data. The contribution on of the graphic sciences to medical research from New York yellow fever to China Coronavirus Disegnarecon, 12:12-11-12.19. 
Das R.D., Bandopadhyay S., Das M., Chowdhury M. (2020). Global Air Quality Change Detection During Covid-19 Pandemic Using SpaceBorne Remote Sensing and Global Atmospheric Reanalysis. In: 2020 IEEE India Geoscience and Remote Sensing Symposium (InGARSS), IEEE, 158-161.

Davies T.M., Lawson A.B. (2019). An evaluation of likelihood-based bandwidth selectors for spatial and spatiotemporal kernel estimates Journal of Statistical Computation and Simulation, 89(1131-1152).

Dong E., Du H., Gardner L. (2020). An interactive web-based dashboard to track COVID-19 in real time The Lancet infectious diseases, 20(533-534)

DuClos C et al. (2021). Peer Reviewed: Mapping Chronic Disease Risk Factors With ArcGIS Online in Support of COVID-19 Response in Florida Preventing Chronic Disease 18.

Elson R., Davies T.M., Lake I.R., Vivancos R., Blomquist P.B., Charlett A., Dabrera G. (2021). The spatio-temporal distribution of COVID-19 infection in England between January and June 2020 Epidemiology \& Infection 149.

Fan C., Li Y., Guang J., Li Z., Elnashar A., Allam M., de Leeuw G. (2020). The impact of the control measures during the COVID-19 outbreak on air pollution in China Remote Sensing, 12(1613).

Feng Z., Xiao C., Li P., You Z., Yin X., Zheng F. (2020). Comparison of spatio-temporal transmission characteristics of COVID-19 and its mitigation strategies in China and the US Journal of Geographical Sciences, 30(1963-1984).

Filippini T., Rothman K.J., Goffi A., Ferrari F., Maffeis G., Orsini N., Vinceti M. (2020). Satellite-detected tropospheric nitrogen dioxide and spread of SARS-CoV-2 infection in Northern Italy Science of The Total Environment, 739(140278).

Filonchyk M., Hurynovich V., Yan H., Gusev A., Shpilevskaya N. (2020). Impact assessment of COVID-19 on variations of SO2, NO2, CO and AOD over East China Aerosol and Air Quality Research, 20, 1530-1540.

Firozjaei M.K., Fathololomi S., Kiavarz M., Arsanjani J.J., Homaee M., Alavipanah S.K. (2021). Modeling the impact of the COVID-19 lockdowns on urban surface ecological status: A case study of Milan and Wuhan cities Journal of environmental management, 286(112236). Franch-Pardo I., Napoletano B.M., Rosete-Verges F., Billa L. (2020). Spatial analysis and GIS in the study of COVID-19. A review Science of The Total Environment, 739 (140033).

Gao S., Rao J., Kang Y., Liang Y., Kruse J. (2020). Mapping county-level mobility pattern changes in the United States in response to COVID-19 SIGSpatial Special, 12, 16-26.

Gelfand M.J. et al. (2021). The relationship between cultural tightness-looseness and COVID-19 cases and deaths: a global analysis The Lancet Planetary Health, 5, e135-e144.

Giuliani D., Dickson M.M., Espa G., Santi F. (2020). Modelling and predicting the spatio-temporal spread of coronavirus disease 2019 (COVID-19) in Italy Available at SSRN 3559569.

Gomes D. et al. (2020). Risk clusters of COVID-19 transmission in northeastern Brazil: prospective space-time modelling Epidemiology \& Infection 148

Graves B.A. (2012). A model for assessment of potential geographical accessibility: a case for GIS Online Journal of Rural Nursing and Health Care, 9(6-55).

Gross B. et al. (2020). Spatio-temporal propagation of COVID-19 pandemics EPL (Europhysics Letters), 131, 8003.

Guan W-j et al. (2020). Clinical characteristics of coronavirus disease 2019 in China New England journal of medicine, 382, $1708-1720$.

He J. et al. (2020). Comparative infection modeling and control of COVID-19 transmission patterns in China, South Korea, Italy and Iran Science of the Total Environment 747:141447.

Ionov D.V. et al. (2021). The CO 2 integral emission by the megacity of St. Petersburg as quantified from ground-based FTIR measurements combined with dispersion modelling Atmospheric Chemistry and Physics Discussions:1-29.

Kanga S., Meraj G., Farooq M., Nathawat M., Singh S.K. (2021). Analyzing the Risk to COVID-19 Infection using Remote Sensing and GIS Risk Analysis.

Kim S., Castro M.C. (2020). Spatiotemporal pattern of COVID-19 and government response in South Korea (as of May 31, 2020) International Journal of Infectious Diseases, 98, 328-333.

Kodge B. (2021). A review on current status of COVID19 cases in Maharashtra state of India using GIS: a case study Spatial Information Research, 29, 223-229.

Kuchler T., Russel D., Stroebel J. (2020). The geographic spread of COVID-19 correlates with the structure of social networks as measured by Facebook. National Bureau of Economic Research.

Kuznetsov I., Panidi E., Kolesnikov A., Kikin P., Korovka V., Galkin V. (2020a). Gis-based infectious disease data management on a city scale, case study of St. Petersburg, Russia The International Archives of Photogrammetry, Remote Sensing and Spatial Information Sciences, 43, 1463-1467.

Kuznetsov I., Panidi E., Korovka V., Galkin V., Voronov D. (2020b). Web-based representation and management of infectious disease data on a city scale, case study of St. Petersburg, Russia The International Archives of Photogrammetry, Remote Sensing and Spatial Information Sciences, 44, 87-91.

Lee W. et al. (2020). COVID-19 in South Korea: epidemiological and spatiotemporal patterns of the spread and the role of aggressive diagnostic tests in the early phase International journal of epidemiology, 49, 1106-1116.

Li W., Thomas R., El-Askary H., Piechota T., Struppa D., Ghaffar K.A.A. (2020). Investigating the significance of aerosols in determining the coronavirus fatality rate among three European Countries Earth Systems and Environment, 4, 513-522.

Liu D., Yang H., Thompson J.R., Li J., Loiselle S., Duan H. (2022). COVID-19 lockdown improved river water quality in China Science of The Total Environment, 802(149585).

Liu Q. et al. (2020). Spatiotemporal Patterns of COVID-19 Impact on Human Activities and Environment in China Using Nighttime Light and Air Quality Data arXiv preprint arXiv:200502808.

Maithani S., Nautiyal G., Sharma A. (2020). Investigating the effect of lockdown during COVID-19 on land surface temperature: study of Dehradun city, India Journal of the Indian Society of Remote Sensing, 48, 1297-1311.

Martines M.R., Ferreira R.V., Toppa R.H., Assunção L., Desjardins M.R., Delmelle E.M. (2021). Detecting space-time clusters of COVID-19 in Brazil: mortality, inequality, socioeconomic vulnerability, and the relative risk of the disease in Brazilian municipalities Journal of Geographical Systems, 23, 7-36.

Masrur A., Yu M., Luo W., Dewan A. (2020). Space-time patterns, change, and propagation of COVID-19 risk relative to the intervention scenarios in Bangladesh International journal of environmental research and public health, 17(5911). 
Mazhar U., Jin S., Bilal M., Ali M.A., Khan R. (2021). Reduction of surface radiative forcing observed from remote sensing data during global COVID-19 lockdown Atmospheric Research, 105729.

Meng T. (2021). Clusters in the Spread of the COVID-19 Pandemic: Evidence From the G20 Countries Frontiers in Public Health, 8(948).

Metya A., Dagupta P., Halder S., Chakraborty S., Tiwari Y.K. (2020). COVID-19 lockdowns improve air quality in the South-East Asian regions, as seen by the remote sensing satellites Aerosol and Air Quality Research, 20, 1772-1782.

Mollalo A., Vahedi B., Rivera K.M. (2020). GIS-based spatial modeling of COVID-19 incidence rate in the continental United States Science of the total environment, $728(138884)$.

Momynaliev K., Khoroshun D., Akimkin V. (2021). Web-queries as an evaluation marker for epidemiological situation of SARS-COV-2 infection in Russia Antimicrobial Resistance and Infection Control.

Mooney P., Juhász L (2020). Mapping COVID-19: How web-based maps contribute to the infodemic Dialogues in Human Geography, $10,265-270$.

Najah A. et al. (2021). Surface water quality status and prediction during movement control operation order under COVID-19 pandemic: Case studies in Malaysia International Journal of Environmental Science and Technology, 18, 1009-1018.

Nakada L.Y.K., Urban R.C. (2020). COVID-19 pandemic: Impacts on the air quality during the partial lockdown in São Paulo state, Brazil Science of the Total Environment, 730, 139087.

Naqvi H.R., Datta M., Mutreja G., Siddiqui M.A., Naqvi D.F., Naqvi A.R. (2021). Improved air quality and associated mortalities in India under COVID-19 lockdown Environmental Pollution, 268, 115691.

NASA (2020). NASA, ESA, JAXA Release Global View of COVID-19 Impacts. https://svs.gsfc.nasa.gov/13647. [Accessed May 8, 2021].

Nath B., Majumder S., Sen J., Rahman M.M. (2021). Risk Analysis of COVID-19 Infections in Kolkata Metropolitan City: A GIS-Based Study and Policy Implications GeoHealth, 5, e2020GH000368.

Nekliudov N.A. et al. (2020). Excessive media consumption about COVID-19 is associated with increased state anxiety: outcomes of a large online survey in Russia Journal of medical Internet research, 22, e20955.

Nichol J.E., Bilal M., Ali M., Qiu Z. (2020). Air pollution scenario over China during COVID-19 Remote Sensing, 12, 2100.

Niroumand-Jadidi M., Bovolo F., Bruzzone L., Gege P. (2020). Physics-based bathymetry and water quality retrieval using planetscope imagery: Impacts of 2020 Covid-19 lockdown and 2019 extreme flood in the Venice Lagoon Remote Sensing, $12,2381$.

Onafeso O.D. et al. (2021). Geographical trend analysis of COVID-19 pandemic onset in Africa Social Sciences \& Humanities Open, 4, 100137.

Oto-Peralías D. (2020). Regional correlations of COVID-19 in Spain.

Parra Boronat M. (2020). Analysis of the evolution of sea water quality in the Spanish coast from satellite images before and during the quarantine caused by COVID-19.

Pramanik M., Udmale P., Bisht P., Chowdhury K., Szabo S., Pal I. (2020). Climatic factors influence the spread of COVID-19 in Russia International journal of environmental health research, 1-15.

Rahman M.H., Zafri N.M., Ashik F.R., Waliullah M., Khan A. (2021a). Identification of risk factors contributing to COVID-19 incidence rates in Bangladesh: A GIS-based spatial modeling approach Heliyon, 7, e06260.

Rahman M.S., Azad M.A.K., Hasanuzzaman M., Salam R., Islam A.R.M.T., Rahman M.M., Hoque M.M.M. (2021b). How air quality and COVID-19 transmission change under different lockdown scenarios? A case from Dhaka city, Bangladesh Science of The Total Environment, 762(143161).

Rose-Redwood R. et al. (2020). Geographies of the COVID-19 pandemic Dialogues in Human Geography, 10(97-106).

Rossman H. et al. (2020). A framework for identifying regional outbreak and spread of COVID-19 from one-minute population-wide surveys Nature Medicine, 26,634-638.

Rui R., Tian M., Tang M.-L., Ho GT-S., Wu C-H. (2021). Analysis of the spread of COVID-19 in the USA with a spatio-temporal multivariate time series model International Journal of Environmental Research and Public Health, 18(774).

Saeed U., Sherdil K., Ashraf U., Younas I., Butt H., Ahmad S. (2021). Identification of potential lockdown areas during COVID-19 transmission in Punjab, Pakistan Public health, 190, 42-51.

Sannino A., D'Emilio M., Castellano P., Amoruso S., Boselli A. (2020). Analysis of Air Quality during the COVID-19 Pandemic Lockdown in Naples (Italy) Aerosol and Air Quality Research, 20.

Sartorius B., Lawson A., Pullan R. (2021). Modelling and predicting the spatio-temporal spread of COVID-19, associated deaths and impact of key risk factors in England Scientific reports, 11, 1-11.

Sathe Y., Gupta P., Bawase M., Lamsal L., Patadia F., Thipse S. (2021). Surface and satellite observations of air pollution in India during COVID-19 lockdown: Implication to air quality Sustainable cities and society, 66(102688).

Shankar K., Gnanachandrasamy G., Mahalakshmi M., Devaraj N., Prasanna M., Chidambaram S., Thilagavathi R. (2021). Meteorological parameters and COVID-19 spread-Russia a case study. In: Environmental Resilience and Transformation in Times of COVID-19. Elsevier, 179190.

Shepherd M. (2020). Why Geography is a key-part of fighting the COVID-19 Coronavirus outbreak Forbes.

Singh R.K. et al. (2020). Prediction of the COVID-19 pandemic for the top 15 affected countries: advanced autoregressive integrated moving average (ARIMA) model JMIR public health and surveillance, 6(e19115).

Sivakumar B. (2021). COVID-19 and water. Springer.

Sun X., Liu J., Wang J., Tian L., Zhou Q., Li J. (2021). Integrated monitoring of lakes' turbidity in Wuhan, China during the COVID-19 epidemic using multi-sensor satellite observations International Journal of Digital Earth, 14(443-463).

Talukdar S., Mahato S., Pal S., Debanshi S., Das P., Rahman A. (2020). Modelling the Global Air Quality Conditions in Perspective of COVID-19 Stimulated Lockdown Periods Using Remote Sensing Data.

Teufel B. et al. (2021). Impact of COVID-19-Related Traffic Slowdown on Urban Heat Characteristics Atmosphere, 12(243).

Tiboni M., Pezzagno M., Vetturi D., Alexander C., Botticini F. (2020). Data analysis and mapping for monitoring health risk. What has the spread of the Covid-19 pandemic in northern Italy taught us? TeMA-Journal of Land Use, Mobility and Environment, 343-360.

Tripathi G., Pandey A.C., Parida B.R. (2020). Spatio-Temporal Analysis of Turbidity in Ganga River in Patna, Bihar Using Sentinel-2 Satellite Data Linked with Covid-19 Pandemic. In: 2020 IEEE India Geoscience and Remote Sensing Symposium (InGARSS), IEEE, $29-32$.

United Nations (2020). The Social Impact of COVID-19. https://www.un.org/development/desa/dspd/2020/04/social-impact-ofcovid-19/. [Accessed May 2021]. 
Vasilyev A. (2021). EXPERIMENTAL RESEARCH OF ENVIRONMENTAL NOISE IN URBAN CONDITIONS BEFORE AND DURING COVID-19 PERIOD ON THE EXAMPLE OF SAMARA REGION OF RUSSIAN FEDERATION Journal Akustika, 39.

Viana J., Santos J.V., Neiva R.M., Souza J., Duarte L., Teodoro A.C., Freitas A. (2017). Remote sensing in human health: A 10-year bibliometric analysis Remote Sensing, 9(1225).

Wagh P., Sojan J.M., Babu S.J., Valsala R., Bhatia S., Srivastav R. (2021). Indicative Lake Water Quality Assessment Using Remote Sensing Images-Effect of COVID-19 Lockdown Water, 13(73).

Wang Y., Liu Y., Struthers J., Lian M. (2021). Spatiotemporal characteristics of the COVID-19 epidemic in the United States Clinical infectious diseases, 72, 643-651.

Wei Z., Kondragunta S., Yang K., Zhang H., McDonald B.C. (2020). Correlating Economic Activity Indicators and Tropospheric Column Nitrogen Dioxide during COVID-19 Pandemic in the United States. In: AGU Fall Meeting Abstracts, A005-0026.

WHO (2020). Report of the WHO-China Joint Mission on Coronavirus Disease 2019 (COVID-19). https://www.who.int/docs/defaultsource/coronaviruse/who-china-joint-mission-on-covid-19-final-report.pdf. [Accessed May 2020]

WHO (2021). WHO Coronavirus (COVID-19) Dashboard. https://covid19.who.int/. [Accessed October 2021].

Wyche K., Nichols M., Parfitt H., Beckett P., Gregg D., Smallbone K., Monks P. (2021). Changes in ambient air quality and atmospheric composition and reactivity in the South East of the UK as a result of the COVID-19 lockdown Science of the Total Environment, 755(142526).

Xu C., Zhang X., Wang Y. (2020). Mapping of health literacy and social panic via web search data during the COVID-19 public health emergency: infodemiological study Journal of Medical Internet Research, 22(e18831).

Xu H., Xu G., Wen X., Hu X., Wang Y. (2021). Lockdown effects on total suspended solids concentrations in the Lower Min River (China) during COVID-19 using time-series remote sensing images International Journal of Applied Earth Observation and Geoinformation, 98(102301).

Yunus A.P., Masago Y., Hijioka Y. (2020). COVID-19 and surface water quality: Improved lake water quality during the lockdown Science of the Total Environment, 731(139012).

Zemtsov S., Baburin V. (2020). COVID-19: Spatial dynamics and diffusion factors across Russian regions Regional Research of Russia, 10(273-290).

Zheng B. et al. (2020). Satellite-based estimates of decline and rebound in China's CO2 emissions during COVID-19 pandemic Science Advances 6:eabd4998. 